Article

\title{
Evolution of Aromatic Profile of Torulaspora delbrueckii Mixed Fermentation at Microbrewery Plant
}

\author{
Laura Canonico $^{1, *}$, Enrico Ciani ${ }^{2}$, Edoardo Galli ${ }^{1}$, Francesca Comitini ${ }^{1}$ and Maurizio Ciani ${ }^{1, *}$ \\ 1 Department of Life and Environmental Sciences, Marche Polytechnic University, Via Brecce Bianche, \\ 60131 Ancona, Italy; edogah@hotmail.it (E.G.); f.comitini@univpm.it (F.C.) \\ 2 Birra dell'Eremo, Microbrewery, Via Monte Peglia, 5, 06081 Assisi, Italy; enrico@birradelleremo.it \\ * Correspondence: 1.canonico@univpm.it (L.C.); m.ciani@univpm.it (M.C.); Tel.: +39-071-2204150 (L.C.); \\ +39-071-2204987 (M.C.)
}

Received: 10 December 2019; Accepted: 6 January 2020; Published: 8 January 2020

\begin{abstract}
Nowadays, consumers require quality beer with peculiar organoleptic characteristics and fermentation management has a fundamental role in the production of aromatic compounds and in the overall beer quality. A strategy to achieve this goal is the use of non-conventional yeasts. In this context, the use of Torulaspora delbrueckii was proposed in the brewing process as a suitable strain to obtain a product with a distinctive aromatic taste. In the present work, Saccharomyces cerevisiae/T. delbrueckii mixed fermentation was investigated at a microbrewery plant monitoring the evolution of the main aromatic compounds. The results indicated a suitable behavior of this non-conventional yeast in a production plant. Indeed, the duration of the process was very closed to that exhibited by S. cerevisiae pure fermentation. Moreover, mixed fermentation showed an increase of some aromatic compounds as ethyl hexanoate, $\alpha$-terpineol, and $\beta$-phenyl ethanol. The enhancement of aromatic compounds was confirmed by the sensory evaluation carried out by trained testers. Indeed, the beers produced by mixed fermentation showed an emphasized note of fruity/citric and fruity/esters notes and did not show aroma defects.
\end{abstract}

Keywords: Torulaspora delbrueckii; craft beer; microbrewery plant; mixed fermentation; aroma profile

\section{Introduction}

In the last years, there has been a worldwide growth in microbreweries, which leads to competition in the beer market to find new beers and also those that are characterized by peculiar aroma taste. To achieve this, the brewers paid attention to the ingredients which are water, malts, hops, and yeast [1-4]. In particular, the brewers focused their attention on the yeast strains to use in brewing fermentation which are selected not only for their good fermentation efficiency but also for their characteristic aroma and flavors.

In this regard, several recent investigations were focused on the selection of non-conventional yeasts [5-8]. Non-Saccharomyces yeasts represent a large source of biodiversity to produce new beer styles. In the last years, different non-Saccharomyces yeasts were proposed in brewing, such as Brettanomyces bruxellensis, Torulaspora delbrueckii, Candida shehatae, Candida tropicalis, Zygosaccharomyces rouxii, Lachancea thermotolerans, Saccharomycodes ludwigii, and Pichia kluyveri [9-13]. T. delbrueckii is one of the most well-known non-Saccharomyces yeasts and it can be found in wild environments such as plants and soils as well as in wine or in fermented food processes. In the brewing process, T. delbrueckii received particular attention due to its ability to ferment maltose, produce ester compounds, and biotransform the monoterpenoid flavor compounds of hops [12,14-16]. In particular, T. delbrueckii can 
improve the amount of different fruity aromas, such as $\beta$-phenyl ethanol ("rose" flavors), n-propanol, iso-butanol, amyl alcohol ("solvent brandy" aroma), and ethyl acetate [17-19].

Canonico et al. [6,12] evaluated the use of $T$ delbrueckii for beer production, both pure and in mixed cultures with different $S$. cerevisiae starter strains. T. delbrueckii in mixed fermentation with different S. cerevisiae starter strains showed different behavior and resulting in beers with distinctive flavors. Generally, the main aromatic compounds that were affected by T. delbrueckii are some fruity esters. Furthermore, in mixed fermentation, T. delbrueckii provided higher levels of higher alcohols, in contrast to data obtained in winemaking, where higher alcohols had lower levels. Moreover, beers obtained with $T$. delbrueckii pure cultures were characterized by a distinctive analytical, aromatic profile, and a low alcohol content $(2.66 \% v / v)$ [12].

Michel et al. [16] investigated different T. delbrueckii strains coming from different habitats. One strain was able to produce a fruity and floral aroma ( $\beta$-phenyl ethanol) and amyl alcohols. Furthermore, two strains were found to be suitable for producing low-alcohol beer owing to their inability to ferment maltose and maltotriose but still produced good flavor. However, investigation into the use of non-conventional yeasts in the brewing process has been performed at a laboratory scale or at a pilot scale while validation trials are lacking at the industrial level, which would give a more accurate assessment of their brewing ability. For this reason and based on the results of previous investigations $[6,12]$ in this study, the contribution of $T$. delbreuckii in mixed fermentation with $S$. cerevisiae starter strain at inoculum ratio 1:20 was assessed at the microbrewery plant. The effect of this non-conventional yeast in mixed fermentation on the evolution of biomass and aroma profile as well as on the final beer composition was evaluated. The sensorial profile of the final beers was also tested.

\section{Materials and Methods}

\subsection{Yeast Strains}

T. delbrueckii DiSVA 254 comes from the Yeast Collection of the Department of Life and Environmental Sciences (DiSVA) of the Polytechnic University of Marche (Italy). T. delbrueckii strain DiSVA 254 and S. cerevisiae commercial strain US-05 (Fermentis, Lesaffre, Marcq En Baroeul, France) were used in mixed fermentation at inoculum ratio 20:1 as reported in a previous study [12]. The US-05 was rehydrated following the manufacturer's instructions and was plated on YPD agar medium at $25^{\circ} \mathrm{C}$, by spreading $0.1 \mathrm{~mL}$ yeast suspension onto the surface of the medium.

The yeast strains were maintained on yeast extract $(10 \mathrm{~g} / \mathrm{L})$, peptone $(20 \mathrm{~g} / \mathrm{L})$, dextrose $(20 \mathrm{~g} / \mathrm{L})$, (YPD) agar $(18 \mathrm{~g} / \mathrm{L})$ at $4{ }^{\circ} \mathrm{C}$, for short-term storage, and in YPD liquid with $80 \%(w / v)$ glycerol at $-80^{\circ} \mathrm{C}$ for long-term storage.

\subsection{Wort Production and Fermentation Condition}

The wort used for the trials was produced at Birra dell'Eremo Microbrewery (Assisi, Italy) from a batch of $1500 \mathrm{~L}$ in duplicate fermentations. The wort was made with pilsner malt $(100 \%)$, the Cascade hop variety, and produced according to the scheme reported by Canonico et al. [6]. The main analytical characters of this wort were $\mathrm{pH} 5.5$, specific gravity $12.3^{\circ}$ GPlato, and 20 IBU. The fermentation process was carried out in 2 different batches of $1500 \mathrm{~L}$ at $20^{\circ} \mathrm{C}$.

\subsection{Growth Kinetics}

The biomass evolution was monitored during the fermentation process using viable cell counts on WL Nutrient Agar (Oxoid, Hampshire, UK) and Lysine Agar (Oxoid, Hampshire, UK). Lysine Agar is a medium unable to support the growth of S. cerevisiae [20] for the differentiation of T. delbrueckii yeast from S. cerevisiae US-05 starter strain. 


\subsection{Bottle Conditioning}

At the end of the fermentation process, the beers obtained were transferred into $500-\mathrm{mL}$ bottles, adding $5.5 \mathrm{~g} / \mathrm{L}$ of sucrose. The secondary fermentation in the bottle was carried out at $18-20{ }^{\circ} \mathrm{C}$ for $7-10$ days.

\subsection{Analytical Procedures}

The contents of acetaldehyde, ethyl acetate, higher alcohols (n-propanol, isobutanol, amyl alcohol, isoamyl alcohol) were determined by direct injection into a gas-liquid chromatography system. The volatile compounds were determined by the solid-phase microextraction (HS-SPME) method. Five ml of each sample was placed in a vial containing $1 \mathrm{~g} \mathrm{NaCl}$ closed with a septum-type cap. HS-SPME was carried out under magnetic stirring for $10 \mathrm{~min}$ at $25^{\circ} \mathrm{C}$. After this period, an amount of 3-octanol as the internal standard $(1.6 \mathrm{mg} / \mathrm{L})$ was added and the solution was heated to $40^{\circ} \mathrm{C}$ and extracted with a fiber Divinylbenzene/Carboxen/Polydimethylsiloxane (DVB/CAR/PDMS) for 30 min by insertion into the vial headspace. The compounds were desorbed by inserting the fiber into the Shimadzu gas chromatograph GC injector for $5 \mathrm{~min}$. A glass capillary column was used: $0.25 \mu \mathrm{m}$ Supelcowax 10 (length, $60 \mathrm{~m}$; internal diameter, $0.32 \mathrm{~mm}$ ). The fiber was inserted in split-splitless mode: $60 \mathrm{~s}$ splitless; the temperature of injection, $220^{\circ} \mathrm{C}$; the temperature of detector, $250^{\circ} \mathrm{C}$; carrier gas, with nitrogen; flow rate, $2.5 \mathrm{~mL} / \mathrm{min}$. The temperature program was $50{ }^{\circ} \mathrm{C}$ for $5 \mathrm{~min}, 3{ }^{\circ} \mathrm{C} / \mathrm{min}$ to $220{ }^{\circ} \mathrm{C}$, and then $220^{\circ} \mathrm{C}$ for $20 \mathrm{~min}$. The compounds were identified and quantified by comparisons with external calibration curves for each compound.

\subsection{Sensorial Analysis}

At the end of the fermentation process, the beers obtained were transferred into $330-\mathrm{mL}$ bottles, adding $5.5 \mathrm{~g} / \mathrm{L}$ sucrose. The secondary fermentation in the bottle was carried out at $18-20{ }^{\circ} \mathrm{C}$ for $7-10$ days. After this period, the beers were stored at $4{ }^{\circ} \mathrm{C}$ underwent sensory analysis using a scale from 1 to 10 (Analytica EBC, 1997). This was carried out by a group of 14 trained testers, that evaluated the main aromatic notes regarding the olfactory and gustatory perception and structural features. The data were elaborated with statistical analyses to obtained information about the contribution of each descriptor on the organoleptic quality of beer.

\subsection{Statistical Analysis}

Analysis of variance (ANOVA) was applied to the main characteristics of the beers. The means were analyzed using the STATISTICA 7 software. The significant differences were determined by the means of Duncan tests, and the results were considered significant if the associated $p$-Values were $<0.05$. The results of the sensory analysis were also subjected to Fisher ANOVA, to determine the significant differences with a $p$-Value $<0.05$.

\section{Results}

\subsection{Yeast Species Evolution}

The growth kinetics of T. delbrueckii in mixed fermentations and S. cerevisiae pure culture were reported in Figure 1.

The growth kinetics of the $S$. cerevisiae US-05 pure cultures achieved ca. $10^{7} \mathrm{CFU} / \mathrm{mL}$ at 3 days of fermentation and decreased at $10^{6} \mathrm{CFU} / \mathrm{mL}$ until the end of fermentation. Regarding the mixed fermentation, S. cerevisiae reached cell concentrations $<106 \mathrm{CFU} / \mathrm{mL}$ at 3 days of fermentation and decreased at $10^{5} \mathrm{CFU} / \mathrm{mL}$, while $T$. delbrueckii, started at a concentration $>10^{6} \mathrm{CFU} / \mathrm{mL}$, achieved the maximum cell concentration at 3 days of fermentation $(107 \mathrm{CFU} / \mathrm{mL})$, and decreased at the end of fermentation $\left(10^{6} \mathrm{CFU} / \mathrm{mL}\right)$. The results for mixed fermentation indicated that $T$. delbrueckii at 
20-folds higher than S. cerevisiae dominated the fermentation process and highlighted a high level of competitiveness of $T$. delbrueckii towards $S$. cerevisiae commercial strain.

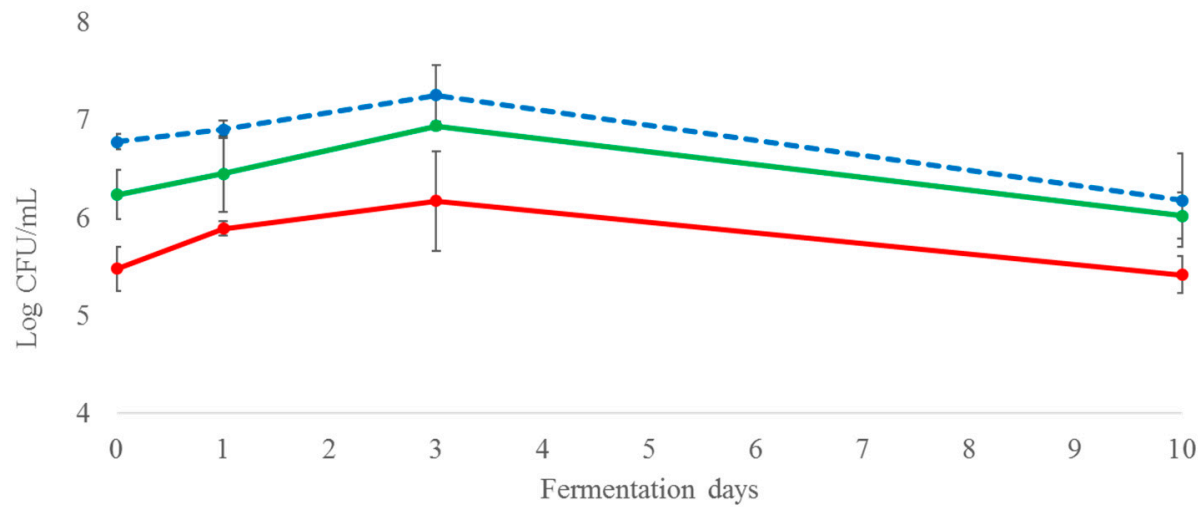

Figure 1. Growth kinetics of pure and mixed fermentation. Pure culture of S. cerevisiae ( - ), S. cerevisiae ( - ) , and T. delbrueckii ( $-\infty-$ ) individually for the mixed fermentation.

\subsection{Main Analytical Profile}

The analytical compositions of the beers are reported in Table 1.

Table 1. The main analytical characteristics of the beer produced by pure and mixed fermentations.

\begin{tabular}{cccccc}
\hline Fermentation & $\begin{array}{c}\text { Wort Gravity } \\
\text { Attenuation }\left({ }^{\circ} \mathbf{P}\right)\end{array}$ & $\begin{array}{c}\text { Ethanol } \\
\% \text { v/v }\end{array}$ & $\begin{array}{c}\text { Residual } \\
\text { Sucrose g/L }\end{array}$ & $\begin{array}{c}\text { Residual } \\
\text { Glucose g/L }\end{array}$ & $\begin{array}{c}\text { Residual } \\
\text { Maltose g/L }\end{array}$ \\
\hline $\begin{array}{c}\text { S. cerevisiae } \\
\text { pure culture }\end{array}$ & $2.85 \pm 0.00$ & $4.75 \pm 0.03$ & $0.00 \pm 0.00$ & $0.00 \pm 0.00$ & $0.06 \pm 0.02$ \\
\hline $\begin{array}{c}\text { S. cerevisiae/T. } \\
\text { delbrueckii }\end{array}$ & $2.79 \pm 0.17$ & $4.68 \pm 0.05$ & $0.24 \pm 0.02$ & $0.02 \pm 0.01$ & $1.36 \pm 0.14$ \\
\hline
\end{tabular}

Data are means \pm standard deviation. The initial composition of the sugars in the wort was sucrose $5.9 \mathrm{~g} / \mathrm{L} ;$ glucose $8.2 \mathrm{~g} / \mathrm{L}$; maltose $61.76 \mathrm{~g} / \mathrm{L}$. The wort gravity at the start was $12.3^{\circ} \mathrm{P}$.

Both trials finished the process on the 10th day of fermentation highlighting that $T$. delbrueckii in the condition used at the microbrewery plant did not influence the time of the fermentation process.

S. cerevisiae/T. delbrueckii mixed fermentation and S. cerevisiae pure fermentation, produce beer with a comparable amount of ethanol content and final values of ${ }^{\circ} \mathrm{P}$. Regarding the residual sugar, both fermentation trials consumed all sucrose and glucose content, while beer brewed by S. cerevisiae/T. delbrueckii mixed fermentation exhibited a slightly higher amount of maltose.

\subsection{By-Products and Volatile Compounds}

The main volatile compound by-products are reported in Table 2.

For the main volatile compound by-products, S. cerevisiae US-05/T. delbrueckii mixed fermentations showed different profiles to those produced by S. cerevisiae US-05 pure fermentation. In particular, the evolution of the main aroma compounds during the fermentation process showed that $\beta$-phenyl ethanol significantly increases in mixed fermentation in all steps of the fermentation process if compared with S. cerevisiae starter strain pure culture. Differently, there were no significant differences between the trials for amyl and isoamyl alcohol content with the exception of $S$. cerevisiae pure culture trials, which exhibited a lower amount of these two alcohols at the first step of fermentation (after one day). 
Table 2. Evolution of the main volatile compounds (mg/L) in the beer produced by pure (S. cerevisiae) and mixed fermentation (S. cerevisiae/T. delbrueckii) during the fermentation process. Data are means \pm standard deviation. Data with different superscript letters $\left({ }^{\mathrm{a}, \mathrm{b}, \mathrm{c}, \mathrm{d}}\right.$, $)$ within each column are significantly different $($ Duncan tests; $p<0.05)$. ND: not detected.

\begin{tabular}{|c|c|c|c|c|c|c|c|c|c|c|c|c|c|}
\hline & & & Alcohols & & & $\begin{array}{l}\text { Carbonyl } \\
\text { Compound }\end{array}$ & & & & ers & & & Terpene \\
\hline Fermentation & 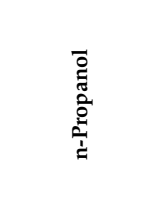 & 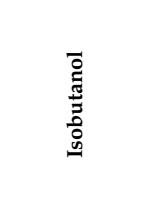 & 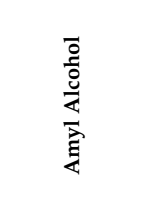 & 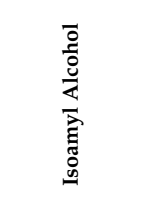 & 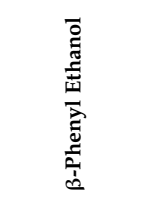 & 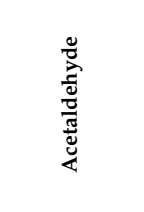 & 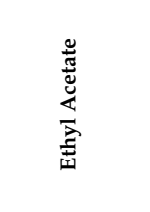 & 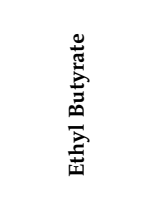 & 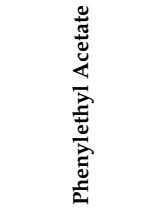 & 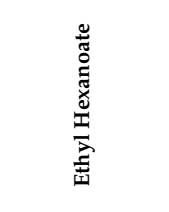 & 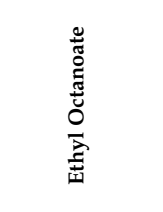 & 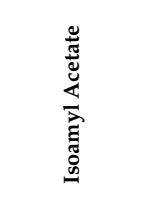 & 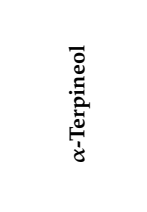 \\
\hline $\begin{array}{l}\text { S. cerevisiae } 1 \text { day } \\
\text { fermentation }\end{array}$ & $\mathrm{ND}$ & $4.51 \pm 0.30^{\mathrm{c}}$ & $2.56 \pm 0.25^{\mathrm{b}}$ & $17.85 \pm 0.06^{b}$ & $3.5 \pm 0.02 \mathrm{e}^{\mathrm{e}}$ & $15.72 \pm 0.43^{\mathrm{a}}$ & ND & $0.144 \pm 0.012^{b}$ & $\mathrm{ND}$ & ND & $0.002 \pm 0.001 \mathrm{~b}$ & $1.70 \pm 0.75^{\mathrm{ab}}$ & ND \\
\hline $\begin{array}{l}\text { S. cerevisiae } 3 \text { days of } \\
\text { fermentation }\end{array}$ & $20.86 \pm 0.29^{c}$ & $13.93 \pm 0.31^{\mathrm{b}}$ & $6.42 \pm 0.60^{\mathrm{a}}$ & $45.82 \pm 0.52^{\mathrm{a}}$ & $15.77 \pm 1.08^{c}$ & $11.44 \pm 1.03^{\mathrm{b}}$ & $3.83 \pm 0.45^{\mathrm{b}}$ & $0.738 \pm 0.123^{\text {a }}$ & ND & ND & $0.043 \pm 0.001 \mathrm{a}$ & $2.79 \pm 0.32 \mathrm{ab}$ & ND \\
\hline $\begin{array}{l}\text { S. cerevisiae } 10 \text { days } \\
\text { fermentation }\end{array}$ & $28.09 \pm 0.16^{a}$ & $27.54 \pm 0.24^{\mathrm{a}}$ & $7.28 \pm 0.13^{\mathrm{a}}$ & $46.72 \pm 0.48^{\mathrm{a}}$ & $17.39 \pm 2.1^{\mathrm{c}}$ & $4.44 \pm 0.98^{\mathrm{d}}$ & $7.42 \pm 0.35^{\mathrm{a}}$ & $0.754 \pm 0.048^{\mathrm{a}}$ & ND & $0.05 \pm 0.03^{b}$ & $0.044 \pm 0.003^{\mathrm{a}}$ & $4.00 \pm 0.24^{\mathrm{a}}$ & ND \\
\hline $\begin{array}{l}\text { S. cerevisiae/T. delbrueckii } \\
1 \text { day of fermentation }\end{array}$ & $24.47 \pm 0.40^{\mathrm{b}}$ & $3.25 \pm 0.15^{\mathrm{d}}$ & $6.85 \pm 0.17^{\mathrm{a}}$ & $46.27 \pm 0.19^{a}$ & $2.15 \pm 0.29^{\mathrm{d}}$ & $7.94 \pm 1.36^{c}$ & $5.62 \pm 0.97^{a}$ & $0.15 \pm 0.03^{b}$ & $0.060 \pm 0.001^{\mathrm{c}}$ & $0.054 \pm 0.006^{b}$ & $0.001 \pm 0.001^{b}$ & $0.32 \pm 0.0^{\mathrm{b}}$ & $0.082 \pm 0.01^{b}$ \\
\hline $\begin{array}{l}\text { S. cerevisiae/T. delbrueckii } \\
3 \text { days fermentation }\end{array}$ & $26.28 \pm 0.22 \mathrm{ab}$ & $27.44 \pm 0.33^{\mathrm{a}}$ & $7.06 \pm 0.15^{\mathrm{a}}$ & $46.49 \pm 0.25^{a}$ & $36.37 \pm 1.02^{b}$ & $6.19 \pm 0.88^{c}$ & $6.52 \pm 0.84^{\mathrm{a}}$ & $0.367 \pm 0.12 \mathrm{ab}$ & $0.405 \pm 0.023^{b}$ & $0.143 \pm 0.08^{a}$ & $0.002 \pm 0.002^{b}$ & $3.85 \pm 0.14^{\mathrm{a}}$ & $0.123 \pm 0.03^{b}$ \\
\hline $\begin{array}{l}\text { S. cerevisiae/T. delbrueckii } \\
10 \text { days of fermentation }\end{array}$ & $25.38 \pm 0.17^{b}$ & $27.52 \pm 0.17^{a}$ & $6.96 \pm 0.12^{\mathrm{a}}$ & $46.38 \pm 0.89^{a}$ & $42.71 \pm 0.98^{a}$ & $7.07 \pm 0.85^{c}$ & $6.07 \pm 0.73^{\mathrm{a}}$ & $0.770 \pm 0.03^{\mathrm{a}}$ & $0.987 \pm 0.124^{a}$ & $0.157 \pm 0.09^{\mathrm{a}}$ & $0.02 \pm 0.002^{\mathrm{b}}$ & $3.56 \pm 0.25^{a}$ & $0.163 \pm 0.03^{a}$ \\
\hline
\end{tabular}


Acetaldehyde content showed a different trend: pure culture trials showed a progressive reduction of this carbonyl compound during the fermentation, while the S. cerevisiae/T. delbrueckii mixed fermentation exhibited the same acetaldehyde content during the process. Ethyl acetate and ethyl hexanoate were detected only in mixed fermentation until the beginning of fermentation. The same trend was also exhibited by $\alpha$-terpineol. Moreover, regarding ethyl hexanoate and $\alpha$-terpineol, there was a significant increase at the end of fermentation. For isoamyl acetate content, the results did not show a significant difference between the two fermentations.

\subsection{Sensory Analysis}

The beers obtained by pure and mixed fermentations underwent sensory analysis, and the results were illustrated in Figure 2.

A

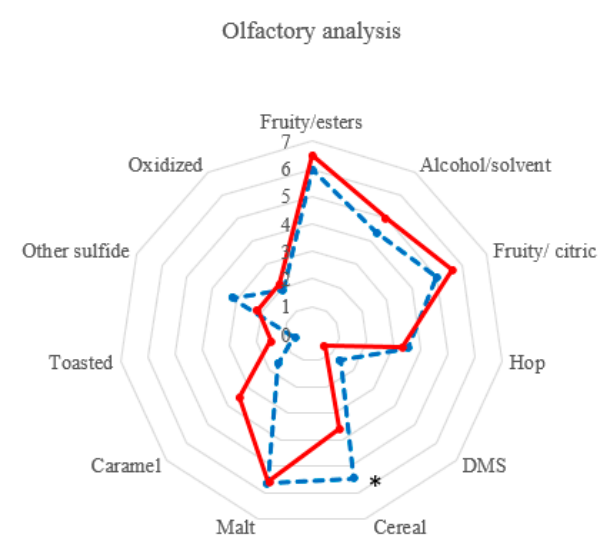

B

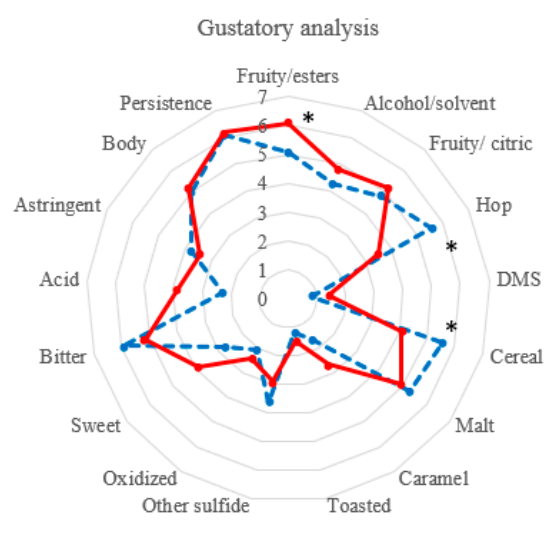

Figure 2. Sensory analysis of beer produced in the microbrewery plant by the T. delbrueckii mixed fermentation. From pure cultures of S. cerevisiae (-- - ) and mixed cultures of S. cerevisiae/T. delbrueckii

( - ). (A) Olfactory analysis; (B) gustatory analysis. DMS, dimethyl sulfide. ${ }^{*}=$ Significantly different (Fisher ANOVA).

All of the beers analyzed showed significant differences for their main aromatic notes regarding the olfactory and gustatory analysis. In particular, for the main sensorial descriptors, the data showed that the beer obtained with the mixed fermentation was significantly different from that of the $S$. cerevisiae US-05 starter strain for a variety of the sensorial characteristics. Regarding olfactory analysis (Figure 2A), beers brewed with S. cerevisiae/T. delbrueckii mixed fermentation showed a bouquet with notes that emphasized the fruity/esters, fruity/citric, and caramel. Moreover, the perception of DMS (dimethyl sulfide) and other sulfide compounds shows they are less well perceived than beers obtained by S. cerevisiae pure culture. However, the only significant difference between the two beers was exhibited by the cereal note, which resulted in the emphasis of the product brewed with the S. cerevisiae starter strain.

Regarding gustatory analysis (Figure 2B), the beers obtained by mixed fermentation are characterized by the significant perception of fruity/esters notes. The beers obtained with S. cerevisiae pure culture were significantly characterized by hop and cereal notes.

In addition, the beers produced by $T$. delbrueckii mixed fermentation were characterized by a pale yellow color, clarity, and persistent and compact foam, which are very important features in the assessment of the quality of a beer (data not shown).

\section{Discussion}

The use of non-conventional yeasts in the brewing process was recently proposed with the aim to produce beers with distinctive aromatics note or to develop a new technology to increase the typicity 
of specialty beers such as low-calorie beer, low alcohol beer, novel flavored beer, and gluten-free beer $[8,12,13,16,21-24]$. In previous studies, the use of $T$. delbrueckii (strain DiSVA 254) in mixed fermentation with $S$. cerevisiae starter strains was investigated at a laboratory scale $[6,12]$. The results indicated a promising behavior of this yeast for use at microbrewery plants. Indeed, the interactions between S. cerevisiae and T. delbrueckii produced beers characterized by a distinctive aromatic profile (fruity/citric notes, fruity/esters notes, and full-bodied attributes) [12]. For these reasons, the application of S. cerevisiae/T. delbrueckii was assessed at the microbrewery plant evaluating the evolution of the volatile compounds during the fermentation process. The first relevant aspect for its application at the industrial level was the duration of fermentation. Similarly, to the laboratory-scale trials, the brewing process carried out with T. delbrueckii mixed fermentation showed a comparable fermentation time to that exhibited by the S. cerevisiae starter strain showing good competitiveness with S. cerevisiae in the co-culture. This aspect is crucial for its application in a microbrewery where for economic reasons the fermentation process should not exceed 10-15 days.

Regarding the evolution of aroma compounds, generally higher alcohols did not show a significant difference between mixed and pure fermentations. Regarding $\beta$-phenyl ethanol content, known for the rose and floral aroma with an odor threshold of $10 \mathrm{mg} / \mathrm{L}$ [18], the results showed an increase in mixed fermentation exhibiting a different trend by a previous study [6,12]. An increase of $\beta$-phenyl ethanol was observed by Toh et al. [25] and Drosou et al. [26] highlighted that the production of this compound was determined by T. delbrueckii and S. cerevisiae strains used in fermentation but also by the fermentation condition.

Esters compounds produced by esterification between alcohol and short- or long-chain fatty acids are important compounds that can affect the aroma of the beer [27]. Phenyl ethyl acetate is known for the floral, sweet, honey, and fruity aroma with a threshold of $3.8 \mathrm{mg} / \mathrm{L} \mathrm{[16]} \mathrm{was} \mathrm{significantly} \mathrm{affected}$ by the presence of T. delbrueckii as previously reported [6,12,26].

This study, confirming a previous study [12], showed the significant increase of ethyl hexanoate, fruity esters associated with apple flavor [27], when T. delbrueckii was used in mixed fermentation while a different trend was observed with different T. delbrueckii and S. cerevisiae strains $[25,26] . \alpha-$ terpineol, the terpene responsible for balsamic/fruit notes, was detected only in mixed fermentation and highlighted that these aroma compounds were related to T. delbrueckii.

Regarding the evolution of the main aroma compounds during fermentation, the S. cerevisiae pure culture and mixed fermentation exhibited a different trend. In particular, the evolution of acetaldehyde content is related to a different metabolic pathway of $S$. cerevisiae and T. delbrueckii. Indeed, in $S$. cerevisiae fermentation the acetaldehyde content decreased during the fermentation process, while in mixed fermentation the content of this carbonyl compound remains similar from beginning to end. The same trend was also exhibited for the main alcohol compounds.

Few works are present in the literature regarding the application of T. delbrueckii in the brewing process and there are no data about its use at the industrial level. These results confirming the fermentation behavior of T. delbrueckii in mixed fermentation, emphasize and reinforce its possible use at the industrial level allowing one to obtain beers with characteristics different from those obtained with S. cerevisiae starter strains and with a sensory profile appreciated by tasters.

Author Contributions: L.C., E.C., E.G., F.C., and M.C. contributed equally to this manuscript. All authors participated in the design and discussion of the research. L.C. carried out the experimental part of the work. E.C. carried out the fermentation in the microbrewery. L.C., E.C., E.G., F.C., and M.C. carried out the analysis of the data and wrote the manuscript. All authors have read and agreed to the published version of the manuscript.

Funding: This research received no external funding.

Acknowledgments: The authors wish to thank the Birra dell'Eremo Microbrewery (Assisi, Italy) for making the microbrewery available and for supporting the technical experimental design. Moreover, thanks go to the UNIONBIRRAI association (Milano, Italy) and the trained testers belonging to UNINOBIRRAI BEER TASTERS (UBT Marche region) for helping the authors to complete the study for an industrial application.

Conflicts of Interest: The authors declare no conflict of interest. 


\section{References}

1. Bernstein, J.M. Imbibe Magazine; Portland, OR, USA, 2010; Volume 2017. Available online: https://www.bjcp. org/ (accessed on 20 November 2019).

2. Brungard, M. Calcium and magnesium in brewing water. New Brew. 2014, 31, 80-88.

3. So, A. Developing new barely varities: A work in progress. New Brew. 2014, 31, 60-68.

4. Osburn, K.; Ahmad, N.N.; Bochman, M.L. Bio-prospecting, selection, and analysis of wild yeasts for ethanol fermentation. Zymurgy 2016, 39, 81-88.

5. van Rijswijck, I.M.; Wolkers-Rooijackers, J.C.; Abee, T.; Smid, E.J. Performance of non-conventional yeasts in co-culture with brewers' yeast for steering ethanol and aroma production. Microb. Biotechnol. 2017, 10, 1591-1602. [CrossRef] [PubMed]

6. Canonico, L.; Comitini, F.; Ciani, M. Torulaspora delbrueckii contribution in mixed brewing fermentations with different Saccharomyces cerevisiae strains. Int. J. Food Microbiol. 2017, 259, 7-13. [CrossRef] [PubMed]

7. Osburn, K.; Amaral, J.; Metcalf, S.R.; Nickens, D.M.; Rogers, C.M.; Sausen, C.; Caputo, R.; Miller, J.; Li, H.; Tennessen, J.M.; et al. Primary souring: A novel bacteria-free method for sour beer production. Food Microbial. 2018, 70, 76-84. [CrossRef]

8. Canonico, L.; Galli, E.; Ciani, E.; Comitini, F.; Ciani, M. Exploitation of Three Non-Conventional Yeast Species in the Brewing Process. Microorganisms 2019, 7, 11. [CrossRef]

9. Sarens, S.; Swiegers, J.H. Enhancement of Beer Flavor by a Combination of Pichia Yeast and Different Hop Varieties. U.S. Patent Application No. 14/241,761, 21 August 2014.

10. De Francesco, G.; Turchetti, B.; Sileoni, V.; Marconi, O.; Perretti, G. Screening of new strains of Saccharomycodes ludwigii and Zygosaccharomyces rouxii to produce low-alcohol beer. J. Inst. Brew. 2015, 121, 113-121. [CrossRef]

11. Domizio, P.; House, J.F.; Joseph, C.M.L.; Bisson, L.F.; Bamforth, C.W. Lachancea thermotolerans as an alternative yeast for the production of beer. J. Inst. Brew. 2016, 122, 599-604. [CrossRef]

12. Canonico, L.; Agarbati, A.; Comitini, F.; Ciani, M. Torulaspora delbrueckii in the brewing process: A new approach to enhance bioflavour and to reduce ethanol content. Food Microbial. 2016, 56, 45-51. [CrossRef]

13. Holt, S.; Mukherjee, V.; Lievens, B.; Verstrepen, K.J.; Thevelein, J.M. Bioflavoring by non-conventional yeasts in sequential beer fermentations. Food Microbial. 2018, 72, 55-66. [CrossRef] [PubMed]

14. King, A.; Dickinson, J.R. Biotransformation of monoterpene alcohols by Saccharomyces cerevisiae, Torulaspora delbrueckii and Kluyveromyces lactis. Yeast 2000, 16, 499-506. [CrossRef]

15. Tataridis, P.; Kanelis, A.; Logotetis, S.; Nerancis, E. Use of non-Saccharomyces Torulaspora delbrueckii yeast strains in winemaking and brewing. Zb. Matitse Srp. Prir. Nauke 2013, 124, 415-426. [CrossRef]

16. Michel, M.; Kopecká, J.; Meier-Dörnberg, T.; Zarnkow, M.; Jacob, F.; Hutzler, M. Screening for new brewing yeasts in the non-Saccharomyces sector with Torulaspora delbrueckii as model. Yeast 2016, 33, 129-144. [CrossRef]

17. Pires, E.J.; Teixeira, J.A.; Brányik, T.; Vincente, A.A. Yeast: The soul of beer's aroma and a review of flavour-active esters and higher alcohols produced by the brewing yeast. Appl. Microbiol. Biotechnol. 2014, 98, 1937-1949. [CrossRef]

18. Etschmann, M.; Huth, I.; Walisko, R.; Schuster, J.; Krull, R.; Holtmann, D.; Wittmann, C.; Schrader, J. Improving 2-phenylethanol and 6-pentyl- $\alpha$-pyrone production with fungi by microparticle-enhanced cultivation (MPEC). Yeast 2015, 32, 145-157. [CrossRef]

19. Basso, R.F.; Alcarde, A.R.; Portugal, C.B. Could non-Saccharomyces yeasts contribute on innovative brewing fermentations? Food Res. Int. 2016, 86, 112-120. [CrossRef]

20. Lin, Y. Detection of wild yeasts in brewery. Efficiency of differential media. J. Inst. Brew. 1975, 81, 410-417. [CrossRef]

21. Petruzzi, L.; Carbo, M.; Sinigaglia, M.; Bevilacqua, A. Brewers' yeast in controlled and uncontrolled fermentation, with a focus on novel, non-conventional and superior strains. Food Rev. Int. 2016, 32, 341-363. [CrossRef]

22. Michel, M.; Meier-Dörnberg, T.; Jacob, F.; Schneiderbanger, H.; Haselbeck, K.; Zarnkow, M.; Hutzler, M. Optimization of beer fermentation with a novel brewing strain Torulaspora delbrueckii using response surface methodology. MBAA TQ 2017. [CrossRef]

23. Senkarcinova, B.; Dias, I.A.G.; Nespor, J.; Branyik, T. Probiotic alcohol-free beer made with Saccharomyces cerevisiae var. boulardii. LWT 2019, 100, 362-367. [CrossRef] 
24. Sannino, C.; Mezzasoma, A.; Buzzini, P.; Turchetti, B. Non-conventional Yeasts for Producing Alternative Beers. In Non-Conventional Yeasts: From Basic Research to Application; Springer: Cham, Germany, 2019; pp. 361-388.

25. Toh, D.W.K.; Chua, J.Y.; Liu, S.Q. Impact of simultaneous fermentation with Saccharomyces cerevisiae and Torulaspora delbrueckii on volatile and non-volatile constituents in beer. LWT 2018, 91, 26-33. [CrossRef]

26. Drosou, F.; Tataridis, P.; Oreopoulou, V.; Dourtoglou, V. Use of wine Non-Saccharomyces yeasts in brewing. In Proceedings of the 36th European Brwery Convention, Antwerpen, Belgium, 2-6 June 2019.

27. Nykänen, L.; Suomalainen, H. Aroma of Beer, Wine and Distilled Alcoholic Beverages; Springer Science \& Business Media, Reidel: Dordrecht, The Netherlands, 1983.

(C) 2020 by the authors. Licensee MDPI, Basel, Switzerland. This article is an open access article distributed under the terms and conditions of the Creative Commons Attribution (CC BY) license (http://creativecommons.org/licenses/by/4.0/). 